\title{
cAMP regulates morphogenesis in the fungal pathogen Ustilago maydis
}

\author{
Scott Gold, ${ }^{1}$ Gillian Duncan, ${ }^{2}$ Katherine Barrett, ${ }^{3}$ and James Kronstad ${ }^{4}$ \\ Biotechnology Laboratory, Departments of Microbiology and Immunology, and Plant Science, University of British \\ Columbia, Vancouver, British Columbia V6T 1Z3, Canada
}

\begin{abstract}
The fungal pathogen Ustilago maydis exhibits a dimorphic switch from budding to filamentous growth in response to mating interactions and environmental conditions. We have found that disruption of the uac1 gene, encoding adenylate cyclase, results in a constitutively filamentous phenotype. Budding is restored to the uac1 mutant upon growth in the presence of cAMP or by extragenic suppression because of a mutation in the ubc1 gene. The ubc1 gene encodes a type II regulatory subunit of cAMP-dependent protein kinase (PKA); defects in this gene attenuate the filamentous growth that normally occurs in response to mating and exposure to air. Growth of wild-type cells in cAMP and mutation of the ubc1 gene also cause defects in the separation of mother and daughter cells (cytokinesis) and alter bud site selection. These results indicate a key role for CAMP and PKA in morphogenesis in $U$. maydis; this role may be common among dimorphic fungal pathogens.
\end{abstract}

[Key Words: Adenylate cyclase; protein kinase A; dimorphism; cytokinesis]

Received August 5, 1994; revised version accepted October 6, 1994.

Many fungi, including saprophytes and pathogens of animals and plants, alternate between filamentous and budding growth morphologies (dimorphism) in response to environmental conditions. For example, Histoplasma capsulatum, the causative agent of human histoplasmosis, has a filamentous form in soil and grows as a budding yeast in host tissue (Maresca and Kobayashi 1989). Candida albicans, which causes candidiasis, exists as hyphal and yeast-like cells in lesions; in vitro, the transition between the two morphologies is influenced by culture conditions, for example, temperature (Cutler 1991). Ustilago maydis, the basidiomycete smut pathogen of maize (Zea mays), exhibits dimorphism in which mating between haploid budding cells establishes a pathogenic, filamentous cell type (Christensen 1963; Holliday 1974). In addition, cells of $U$. maydis will switch between budding and filamentous forms in response to environmental conditions such as nutrient availability (Kernkamp 1939) and exposure to air (S. Gold, this study). The study described here takes advantage of the dimorphic transition in $U$. maydis to identify genes involved in the regulation of budding versus filamentous growth.

The filamentous cell type in $U$. maydis is established primarily through mating interactions governed by two genetic loci called $a$ and $b$. Budding haploid cells are compatible to fuse and to form the filamentous dikaryon

Present addresses: ${ }^{1}$ Department of Biology, University of California, San Diego, La Jolla, California 92093-0116 USA; ${ }^{2}$ Unité de Virologie Médicale, Institut Pasteur, 75724 Paris, CEDEX 15 France; ${ }^{3}$ Pacific Agriculture Research Centre, Vancouver, British Columbia, Canada. ${ }^{4}$ Corresponding author. only if they carry genes with different specificities at both the $a$ and $b$ loci. Cell fusion is controlled by the $a$ mating-type locus, which has two alternative forms, $a 1$ and $a 2$. The $a 1$ and $a 2$ sequences have recently been shown to be idiomorphs (Froeliger and Leong 1991) and to encode pheromones and pheromone receptors (Bölker et al. 1992; Spellig et al. 1994). The $b$ locus appears to control events after cell fusion necessary for establishment of the filamentous, pathogenic cell type (termed the infectious dikaryon). The $b$ locus encodes two products, $\mathrm{bE}$ and $\mathrm{bW}$; the interaction of the $\mathrm{bE}$ product from one form of the $b$ locus with the bW product from another is believed to establish a novel regulatory protein that triggers formation of the infectious dikaryon /Gillissen et al. 1992). The alignment of the predicted amino acid sequences of several alleles of the $b E$ or $b W$ genes revealed that each contains a variable amino-terminal region, a central homeo domain-like motif, and a conserved carboxy-terminal region (Kronstad and Leong 1990; Schulz et al. 1990; Gillissen et al. 1992). Recognition mediated by the products of the $b$ genes is of particular interest because there are at least 25 different specificities at the $b$ locus (Puhalla 1970; Silva 1972). Specificity is mediated by the variable amino-terminal region of $b E$ as demonstrated by the construction of chimeric alleles of the $b E 1$ and $b E 2$ genes (Yee and Kronstad 19931. These experiments identified an $\sim 40$-amino-acid region in the amino-proximal region that is believed to determine the specificity of interaction between the $b E$ and $b W$ gene products. That is, the specificity region may control whether the heterodimer of $\mathrm{bE}$ and $\mathrm{bW}$ poly- 
peptides is active in maintaining filamentous growth (Gillissen et al. 1992; Yee and Kronstad 1993).

The filamentous cell type established by the action of the $a$ - and $b$-encoded functions is the only infectious stage of the life cycle. This cell type causes a localized infection on maize plants typified by the formation of large tumors or galls on any above-ground part of the plant (Christensen 1963). The fungus proliferates within gall tissue, and as galls mature, the nuclei of the dikaryon fuse and diploid teliospores are formed. Upon dispersal from the host plant, the diploid teliospores may germinate, form promycelia, and undergo meiosis to yield haploid budding cells.

Recently, we described mutants in $U$. maydis that display a constitutively filamentous phenotype (Barrett et al. 1993). Colonies of these mutants become covered with white aerial mycelium in contrast with the flat gray morphology of colonies formed by wild-type parental cells. Interestingly, one of the mutations (rem1-1) was found to block pathogenicity, even though the cells displayed a filamentous morphology similar to that of the infectious dikaryon. Complementation of the rem1-1 mutation with a cosmid library and subsequent disruption experiments with the cloned gene also yielded mutants with filamentous growth morphologies. Sequence analysis of the complementing region, reported in this paper, reveals that the cosmid carries a homolog of adenylate cyclase. Therefore, we have replaced the rem 1 designation for the gene with uac1 for Ustilago adenylate cyclase.

In addition to the characterization of the uac1 gene that encodes adenylate cyclase, we describe the influence of exogenous CAMP on the morphogenesis of wildtype cells and on a filamentous mutant carrying a disruption in the uac1 gene. We find that cAMP restores budding growth to the filamentous mutant and alters bud site selection and mother-daughter separation (cytokinesis) in wild-type cells. The latter phenotype is also found in mutants that contain an extragenic suppressor of the defect in adenylate cyclase. The defective gene in one of these mutants was found to have sequence similarity to the regulatory subunit of CAMP-dependent protein kinase (PKA). The mutation in this gene, which has been designated $u b c 1$ (Ústilago bypass of cyclase), also attenuates filamentous growth resulting from mating interactions and from exposure to air. Overall, our results suggest a general role for CAMP and PKA in the regulation of dimorphism for $U$. maydis.

\section{Results}

Filamentous growth results from a defect in adenylate cyclase

Wild-type haploid cells of $U$. maydis divide by the formation of an elongated bud at an oblique angle at or near one end of the mother cell. In contrast, and as described by Barrett et al. (1993), haploid strains carrying a disruption of the uac1 (rem1) gene grow exclusively by hyphal extension. Figure 1 shows a comparison of the morphol- ogies displayed by wild-type budding cells $(A, B)$, cells carrying a disruption of the uac1 gene $(\mathrm{C}, \mathrm{D})$, and cells of the disruption mutant carrying a complementing cosmid, pFuz60 (E,F). It is clear that a mutation in the uac1 gene dramatically alters the morphology of $U$. maydis and results in a constitutively filamentous phenotype.

The nucleotide sequence of $\sim 10 \mathrm{~kb}$ of genomic DNA from the complementing region of cosmid pFuz60 (identified by subcloning/ was determined and found to contain one long open reading frame of $7479 \mathrm{bp}$. The amino acid sequence of the predicted polypeptide (2493 amino acids) showed extensive similarity to adenylate cyclases from other fungal species. The size of the predicted polypeptide is similar to that of the adenylate cyclases from Neurospora crassa (2300 amino acids; Kore-eda et al. 1991) and Saccharomyces cerevisiae (2026 amino acids; Kataoka et al. 1985). In addition, the predicted polypeptide contains leucine-rich tandem repeats in the central portion of the sequence (between codons 1219 and 1517); these leucine-rich motifs are similar in sequence and organization to the leucine-rich repeats identified in the adenylate cyclases from $S$. cerevisiae and $N$. crassa (Kataoka et al. 1985; Kore-eda et al. 1991). An alignment of a portion of the predicted amino acid sequence of uac1 with the sequences encompassing the catalytic domains of adenylate cyclases from $N$. crassa (Kore-eda et al. 1991) and S. cerevisiae (Kataoka et al. 1985) is shown in Figure 2. The disruption mutation in the uac1 gene was constructed by insertion of a selectable marker for phleomycin resistance at codon 899 (Fig. 2); insertion at this position would block expression of the carboxy-terminal two-thirds of the polypeptide including the predicted catalytic domain. Overall, the finding that uac1 encodes a homolog of adenylate cyclase and that a mutation in uac1 results in filamentous growth provides strong evidence for a role for cAMP in the control of morphogenesis in $U$. maydis.

CAMP suppresses the defect in adenylate cyclase and promotes a multiple-budding phenotype

The discovery of sequence homology of the $U$. maydis uac1 gene to adenylate cyclase prompted an analysis of the response of the uac1 disruption strain to exogenous cAMP. As shown in Figure $1(\mathrm{G}, \mathrm{H})$, addition of $25 \mathrm{~mm}$ cAMP to the culture medium caused the cells of the uac1 mutant to display a budding phenotype. Addition of $25 \mathrm{mM}$ AMP (Fig. 1G, inset) or cGMP (data not shown) failed to influence the filamentous phenotype of the mutant cells. We conclude that cAMP influences budding growth in $U$. maydis; the phenotype of the mutant in the presence of cAMP suggests that high levels of cAMP promote budding growth and low levels condition filamentous growth.

An interesting phenotype is observed when wild-type cells are exposed to the same level of cAMP employed to restore budding growth to the uac1 disruption strain. That is, wild-type cells grown in 25 mM cAMP show a distinctive phenotype in which mother and daughter 

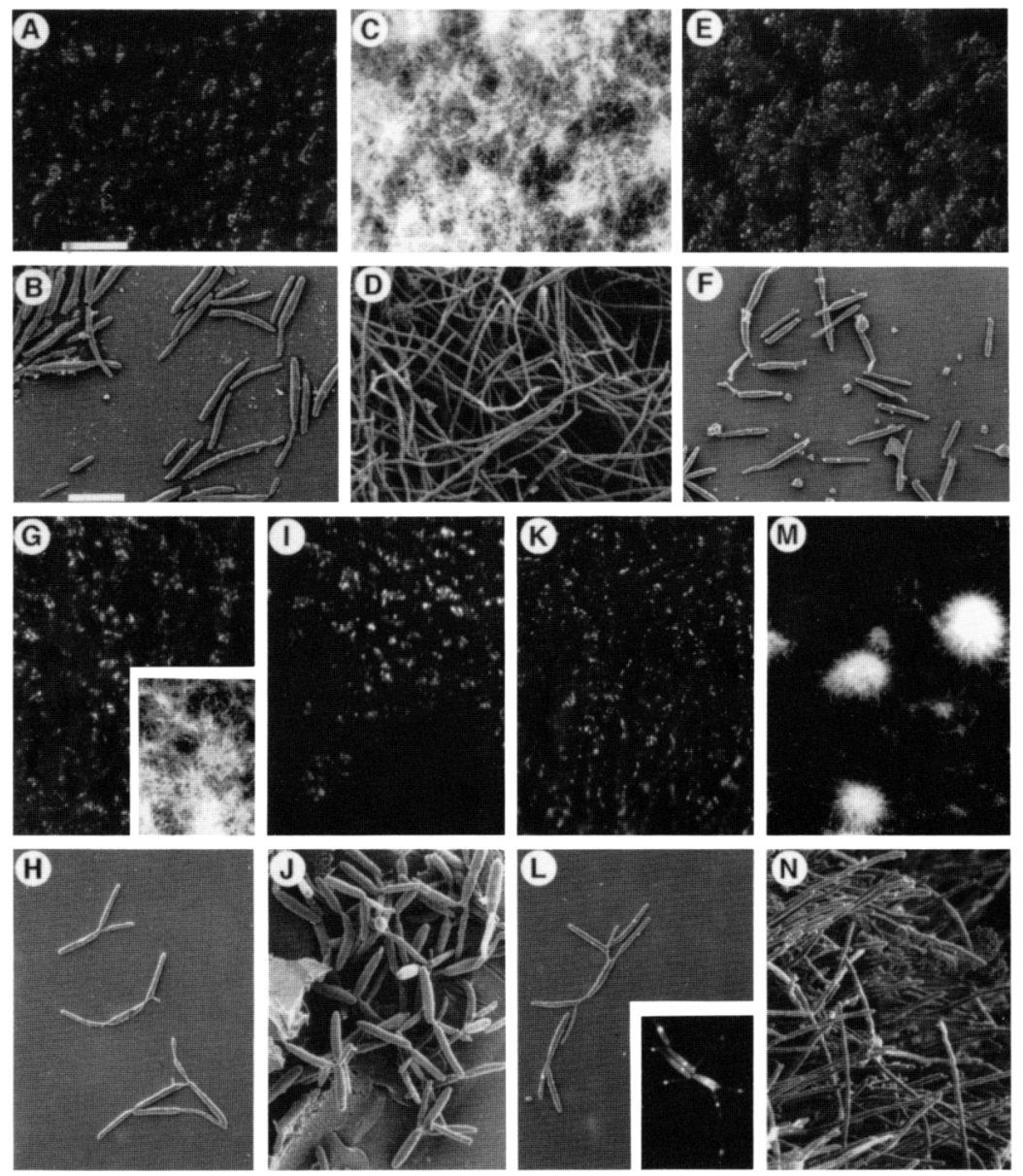

Figure 1. Influence of cAMP and mutations in uac1 and ubc1 on the morphology of $U$. maydis. $(A, C, E, G, I, K, M)$ Photographs of the colony morphology of $U$. maydis strains grown on PDA (bar, $0.5 \mathrm{~mm}) .(B, D, F, H, J, L, N)$ Scanning electron micrographs of cells grown in PDB (bar, $10 \mu \mathrm{m})$. The following strains are shown: $(A, B) 521$ (wild type); $(C, D)$ C002P, uac1::ble; $(E, F)$ C002P carrying the pFuz60 cosmid; $(G, H)$ C002P grown on medium containing $25 \mathrm{mM}$ cAMP (inset in $G$ is a control in which 25 mM AMP is present in the medium $)_{i}(I, J)$ 521 grown with $25 \mathrm{mM}$ cAMP; $(K, L)$ C002a (uac1::ble ubc1-1; inset in $L$ shows DAPI-stained nuclei); $(M, N)$ C002a (uac1::ble ubc1-1) carrying the pUBC1 cosmid. Note that all of the mutants are derivatives of strain 521 . cells remain attached in clusters of more than two cells and lateral as well as apical sites are used for bud formation (Fig. 1I,J). This result is striking because it is rare to observe clusters of more than two cells or the use of lateral bud sites in cultures of wild-type cells. The phenotype of cells exposed to cAMP is referred to as multiple budding (Fig. 1J) and apparently results from failure of cytokinesis of mother and daughter cells prior to the formation of subsequent buds. It appears that daughter cells can begin to bud prior to separation from mother cells (Fig. 1, cf. B with J). It should be noted that the multiple-budding phenotype can also be observed with the uac1 disruption mutant grown in the presence of 25 mM cAMP (Fig. 1H). Lower concentrations (e.g., $1 \mathrm{~mm}$ cAMP) generally cause cells of the disruption mutant to partially return to a budding phenotype, without the appearance of cells with multiple buds (S. Gold, unpubl.).

\section{Filamentous growth is suppressed by a mutation} in the ubcl gene

Suppressor mutations that restored budding growth to the uac1 disruption mutant were readily obtained. These mutations cause cells to form flat yeast-like colonies
(Fig. $1 \mathrm{~K}$ ) that are easily distinguished from the mycelial colonies of the parental uac1::ble strain (Fig. 1C). A collection of 46 suppressor mutants with various cellular morphologies was obtained and the mutations in these strains were designated $u b c$ for Ustilago bypass of cyclase. The double mutant shown in Figure $1(\mathrm{~K}, \mathrm{~L})$ carries the $u b c 1-1$ allele and displays a multiple-budding phenotype similar to that observed upon treatment of cells of a wild-type strain, or the uac1 disruption strain, with cAMP. Staining with DAPI revealed that in general, each cell of the $u b c 1-1$ strain contains a single nucleus (Fig. $1 \mathrm{~L}$, inset), indicating that the newly formed cells are actual buds.

The ubc1-1 mutation was complemented with a cosmid library by screening for transformants that regained the filamentous phenotype of the uac1 disruption strain (Fig. 1M,N). Sequence analysis of a $3-\mathrm{kb}$ genomic region that complemented the $u b c 1-1$ defect (identified by subcloning) revealed a 1566 -bp open reading frame (Fig. 3), and RNA blot hybridization analysis using a probe from this region identified an $\sim 2.1-\mathrm{kb}$ transcript (data not shown). The amino acid sequence of the predicted ubcl polypeptide (522 amino acids) shows significant similarity to the regulatory subunit of PKA. In addition, the presence of a serine residue at position 170 
A

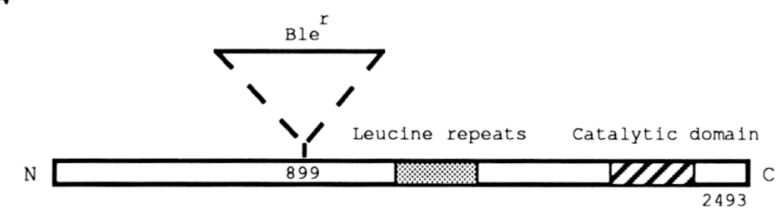

$\mathbf{B}$

SC 1609 MAYGCTENITILCLA...TYENIQQQNRETTN ........

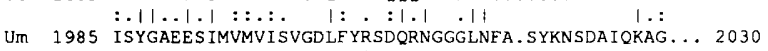

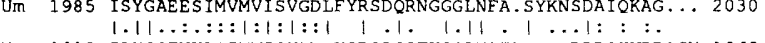

NC 1813 IAYGSTNKLLIMMIGVANLKQRQAQQFKGQLNATF SMPQDDP SHVPPSGN 1862

SC 1641 ..LMTRRSTFEDTTLRRLQPEISPPTGNLAMVFTDIKSSTFLWELFPNAM 2688

Um $2031 \ldots$ RRFREELPGDRTLARLDREVAPPIGQVALVFTD IKNSTSLWET. NNGM 2077

NC

SC 1689 RTAIKTHNDIMRRQLRIYGGYYVVTEGDAFMVAFPTPTSGLTWCLSGQLK 1738 I1:: $11:: 11111 \ldots 1111111111+111.11 \ldots: 111: \ldots 1$

Um 2078 OTAMRLHNYLLRRQLRTIGGYEVKIECDAFUSEP SVSAALLWCFTVQ00 2127

(1) 1962

SC 1739 LLDAQWPEEITSVQDGCOVTDRNGNIIYOGLSVRMGIHWGCPVPELDLVT 1788

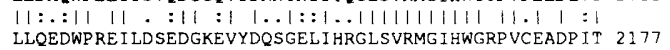

Um 2128 LLQEDWPREILDSEDGKEVYDQSGELI HRGLSVRMGIHWGRPVCEADPI 2177 NC 1963 LLTVDWPPEVLSNSSCOP IYDRNNNLITRGLSVRMGAHWGEP LAERDPVT 2012

SC 1789 QRMDYLGPMVNKAARVQGVADGGQIAMSSDFYSEFNKIM.KYHERVVKGK 1837

SC $1111: 11111: 111: 1.111111$ 1.1...1: : : .:. . . I

Um 2178 RRMDYFGPMVNRARISGAADGGQILASKDVIKELQGLLGTFDESSTAGG 2227

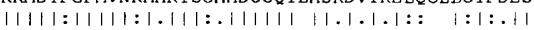

NC 2013 RRMDYYGPMVNKASRI SAVADGGQITASSDF ITE I HRCLETYKES. . . 2057

SC $1838 \ldots \ldots$ ES LKEVYGEE ... II IGEVLERE I AMLES IGWAFFDFGEHKIK 1876

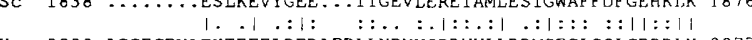

Um 2228 AGGEGENLEKTEEELDEDAFRLLNPNVSRDVVLLRRMGFGLSQLGERRL

NC $2058 \ldots \ldots$ VDVDEDSLEDDA...TAKAIRAELRALSSQGFEVKMGEKKLK 2097

SC 2877 GLETKELVTIAYP 1889

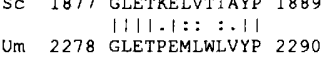

$111,11::: 111$

NC 2098 GLENPELVYSVYP 2110

Figure 2. Map of the uac1 open reading frame and homology among catalytic domains of three fungal adenylate cyclases. $(A)$ The open reading frame is shown for the uac1 gene along with the position of insertion of the phleomycin (ble) resistance gene, the leucine-rich repeats, the catalytic domain region employed in the sequence alignment, and the partial cDNA for the uac1 gene. $(B)$ Sequence alignment of the predicted catalytic domain (codons 1985-2290) encoded by the U. maydis uac1 gene (Um) with the corresponding domains from the $S$. cerevisiae $(\mathrm{Sc})$ and $N$. crassa $(\mathrm{Nc})$ genes. The uac1 region shows $47 \%$ sequence identity with the corresponding region of the $S$. cerevisiae adenylate cyclase sequence and $52 \%$ identity with the $N$. crassa sequence. The overall identity between the entire predicted polypeptides for $S$. cerevisiae and $U$. maydis is $33 \%$; the $U$. maydis and $N$. crassa polypeptides are $34 \%$ identical. The absence of introns in the region used for alignments (encoding amino acids 1646-2493) was confirmed by sequence analysis of the cDNA and comparisons of restriction fragment sizes between cDNA and genomic versions of the gene. Sequence inspection of the remaining portion of the coding region revealed only one region that could potentially contain an intron. Splicing of this putative intron (between codons 1448 and 1503) would not change the reading frame of the polypeptide but would remove 54 amino acids from the coding region. Sequence analysis was performed with the GAP program from the Genetics Computer Group, University of Wisconsin (Devereux et al. 1984). indicated that the $u b c 1$ gene encodes a type II regulatory subunit (Taylor et al. 1990). Overall, the finding that the $u b c 1$ gene encodes a regulatory subunit of PKA provides strong additional evidence that the CAMP pathway plays an important role in the regulation of dimorphic growth in $U$. maydis. We infer from these results that the catalytic subunit of PKA, when dissociated from the regulatory subunit in the presence of cAMP, is required for budding growth, establishment of a polar bud position, and completion of cytokinesis.

\section{Cytokinesis and bud site selection require the ubcl gene}

The multiple-budding phenotype resulting from mutation in the $u b c 1$ gene and from growth on medium containing cAMP has been examined in more detail in terms of the appearance of cells with multiple buds at different stages of growth, the number of cells per cluster, and the frequency of lateral buds (Fig. 4; Table 1). As shown in Figure 4A, wild-type cells (strain 521) generally showed single apical buds. This budding phenotype was evident throughout growth (Table 1). In addition, wild-type strains generally appeared as single cells or pairs of cells (mother and daughter). In contrast, wild-type cells grown in the presence of $25 \mathrm{mM}$ cAMP displayed the multiplebudding phenotype in which clusters of cells were observed, particularly at high cell densities, in actively growing cultures (Fig. 4B; Table 1). These cells also showed a high percentage of lateral buds (Table 1). In general, the average number of cells per group was lower in the cultures at an early time after inoculation $(8 \mathrm{hr})$ and in cells that had been in culture for extended periods (e.g., $48 \mathrm{hr}$ ). The average number of cells per group was highest in 22-hr cultures; this time corresponds to late exponential growth.

$U$. maydis strains carrying mutations in both the uac1 and $u b c 1$ genes (C002a, Fig. 4C), or in the $u b c 1$ gene alone (111, Fig. 4D), had phenotypes similar to wild-type cells grown in cAMP (Figure 4B) at each of the sampling times (Table 1). That is, these cells displayed the multiple-budding phenotype with frequent misplacement of buds to lateral positions. The cellular morphology of strain C002a, which carries the disruption of uac1 gene as well as the $u b c 1-1$ mutation, had a slightly different phenotype in that many of the cells were somewhat elongated (Figs. 4C and $1 \mathrm{~K}, \mathrm{~L}$ ). These cells appeared to be partially filamentous compared with cells that only carry the $u b c 1-1$ mutation. This phenotype may result from the opposing influences of a defect in the uac1 gene, which would result in reduced cAMP levels and low PKA activity, and a defect in the $u b c 1$ gene, which would alleviate normal regulation of PKA and cause elevated activity.

The disruption mutation (ubc1::hyg; strain 521d) was constructed in $u b c 1$ (Fig. 3) to confirm that a defect in the regulatory subunit of PKA would result in the phenotype observed with a $u b c 1-1$ mutant. The insertion mutation in strain $521 \mathrm{~d}(u b c 1:: h y g)$ is at codon 360 , a site that is between the two cAMP-binding domains (Fig. 
A

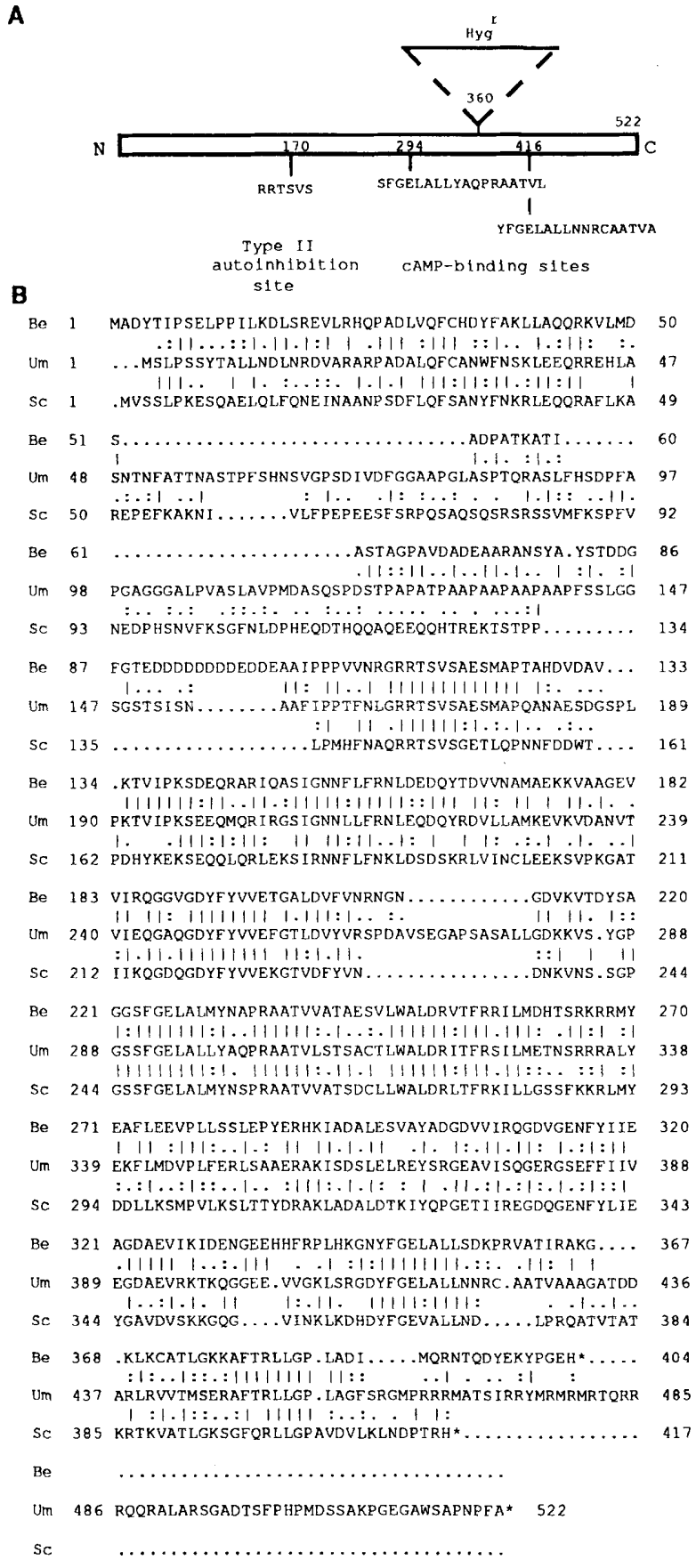

3). Given the position of the insertion, it is possible that the $u b c 1::$ hyg allele encodes a regulatory subunit of PKA that retains partial activity, assuming that a polypeptide is produced from the disrupted gene and that the remaining cAMP-binding site is functional. However, strain 521d (ubc1::hyg) displayed a similar pattern of multiple budding and lateral bud site selection (Table 1; Fig. 4E) when compared with strain 111 (ubc1-1), a phleomycinsensitive, haploid segregant from a cross between strain C002a $\{a 1$ b1 uac1::ble ubc1-1) and the wild-type strain
Figure 3. Map of the $u b c 1$ open reading frame and sequence similarity among three fungal regulatory subunits of PKA. $(A)$ The open reading frame of the $u b c 1$ gene and the positions of key features of type II regulatory subunit genes such as the autoinhibition site (phosphorylation site) and the cAMP-binding sites (Taylor et al. 1990). The presence of the serine residue at codon 170, which is the target of phosphorylation by the catalytic subunit, indicates that $u b c 1$ encodes a type II regulatory subunit. The 6-amino-acid sequence shown is identical to that found in the yeast $B C Y 1$ gene (Toda et al. 1987). The sequences at the cAMP-binding sites are also shown (aligned at the conserved glutamic acid residues at codons 294 and 416). The position of insertion of the hygromycin resistance gene is also shown (codon 360); this insertion mutation is between the the cAMP-binding domains and was used to construct the gene disruption in stain $521 \mathrm{~d}$ ( $u b c 1:: h y g)$. (B) Sequence alignment of the predicted product of the $U$. maydis $u b c 1$ gene (Um) with the polypeptides from Blastocladiella emersonii (Be; Marques and Gomes 1992) and S. cerevisiae (Sc; Toda et al. 1987). The polypeptide predicted for $u b c 1$ is $38 \%$ identical to that of the $B C Y 1$ gene of $S$. cerevisiae and $51 \%$ identical to the regulatory subunit of $B$. emersonii. The region between codons 48 and 155 of the $u b c 1$ polypeptide shows extensive gaps when aligned with the other sequences; an intron is found in this region in many PKA regulatory subunit genes. The absence of an intron in this region (codons 12-246) for the $u b c 1$ gene was confirmed by RT-PCR. That is, identical size PCR fragments from this region were obtained from genomic and CDNA templates (data not shown).

518 (a2 b2) (Fig. 4D). It is possible that the $u b c 1-1$ allele might also encode a polypeptide truncated at a similar position to the one encoded by the ubc1::hyg allele. Overall, the results with the disruption mutant confirm that a defect in the gene encoding the regulatory subunit of PKA results in cells with a multiple-budding phenotype. In combination with the results for the uac1 gene, these data indicate a role for cAMP and regulated PKA activity in cytokinesis and in the positioning of the bud site in $U$. maydis. 
Figure 4. Multiple-budding phenotype of the PKA regulatory subunit mutants. Phase-contrast micrographs are shown for cells grown in PDB for $22 \mathrm{hr}$ (Table 1). Individual panels show the following strains: (A) 521 ; (B) 521 with $25 \mathrm{~mm}$ cAMP; $(C)$ C002a (uac1::ble ubc1-1); (D) 111 ubc1-1; (E) 521d ubc1::hyg. Bar, $20 \mu \mathrm{m}$.

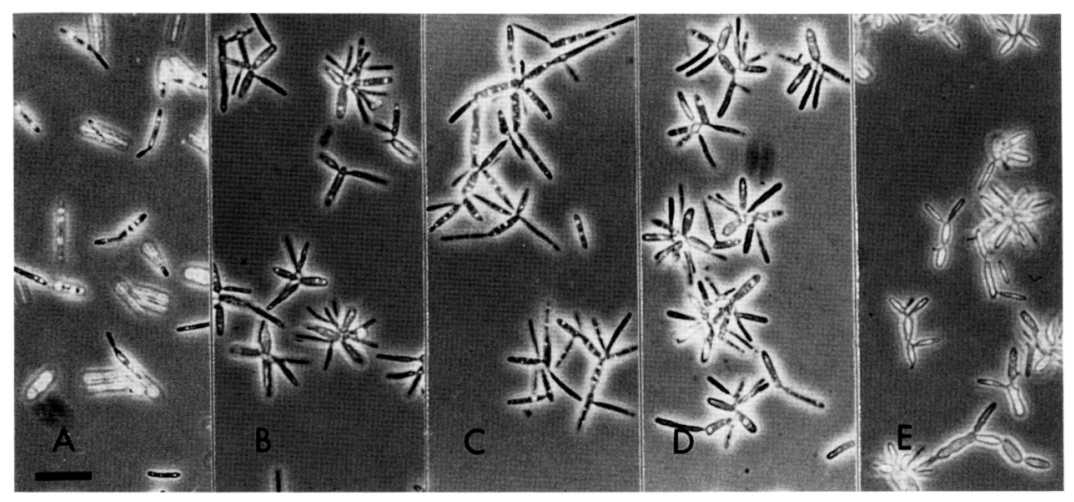

Filamentous growth in response to mating and air requires ubc 1

The ability of $U$. maydis to form the infectious, filamentous cell type depends on mating interactions between compatible haploid strains of opposite mating type. Compatible interactions result in the formation of mycelial colonies on culture medium containing activated charcoal (Fig. 5A). This mating assay was employed to determine whether strains carrying the $u b c 1-1$ allele or both the ubc1-1 allele and the uac1::ble allele were capable of forming mycelial colonies when paired with wild-type strains or with similar mutants of opposite mating type. As shown in Figure 5A, a mixture of compatible mutant strains (each of genotype uac1::ble ubc11) resulted in colonies with a greatly attenuated mycelial phenotype. The same result was obtained with mixtures of compatible strains that each carry only the $u b c 1-1$ allele. In contrast, each strain, whether a double mutant (uac1::ble ubc1-1) or only carrying the $u b c 1-1$ allele, was capable of forming strongly mycelial colonies when paired with wild-type strains of opposite mating type (Fig. 5A).

These results indicate that the formation of aerial hyphae on mating colonies, which is a measure of formation of both mating hyphae (conjugation tubes) and infection hyphae (the infectious dikaryon; Snetselaar and Mims 1992), is at least partially dependent on the $u b c 1$ gene and, by inference, on correctly regulated PKA activity. We have also found that inoculation of maize seedlings with strains that carry the $u b c 1-1$ mutation results in greatly attenuated disease symptoms, although some filamentous cells are observed in plant tissue (S. Gold, D. Mills, and J. Kronstad, unpubl.). These observations indicate that $u b c 1$ mutants are defective in an as yet unidentified step in the formation or maintenance of the infectious dikaryon. The implication is that there may be an interaction between the cAMP pathway and

Table 1. Quantitation of multiple and lateral budding

\begin{tabular}{|c|c|c|c|c|c|c|c|}
\hline Strain & $\begin{array}{c}\text { Time } \\
\text { (hr) }\end{array}$ & $\begin{array}{l}\text { Cell } \\
\text { density }^{a}\end{array}$ & $\begin{array}{l}\text { Cells } \\
\text { counted }^{b}\end{array}$ & $\begin{array}{l}\text { Total } \\
\text { units }\end{array}$ & $\begin{array}{l}\text { Average } \\
\text { cells/unit }\end{array}$ & $\begin{array}{l}\text { Lateral } \\
\text { buds }\end{array}$ & $\begin{array}{l}\text { Maximum } \\
\text { cells/unit }\end{array}$ \\
\hline \multirow[t]{3}{*}{521} & 8 & $7.5 \times 10^{6}$ & 150 & 93 & 1.6 & 1 & 5 \\
\hline & 22 & $1.9 \times 10^{8}$ & 153 & 129 & 1.2 & 0 & 2 \\
\hline & 48 & $2.6 \times 10^{8}$ & 103 & 98 & 1.1 & 0 & 2 \\
\hline \multirow[t]{3}{*}{$521+\mathrm{cAMP}^{\mathrm{c}}$} & 8 & $8.7 \times 10^{6}$ & 174 & 50 & 3.5 & 25 & 19 \\
\hline & 22 & $2.1 \times 10^{8}$ & 171 & 24 & 7.1 & 62 & 13 \\
\hline & 48 & $3.4 \times 10^{8}$ & 205 & 35 & 5.9 & 62 & 17 \\
\hline \multirow[t]{3}{*}{$\mathrm{COO2a}$} & 8 & $8.7 \times 10^{5}$ & 121 & 43 & 2.8 & 23 & 9 \\
\hline & 22 & $1.3 \times 10^{8}$ & 102 & 39 & 2.6 & 16 & 7 \\
\hline & 48 & $2.5 \times 10^{8}$ & 147 & 110 & 1.3 & 5 & 5 \\
\hline \multirow[t]{3}{*}{111} & 8 & $2.0 \times 10^{6}$ & 195 & 47 & 4.1 & 49 & 10 \\
\hline & 22 & $1.4 \times 10^{8}$ & 230 & 34 & 6.8 & 63 & 47 \\
\hline & 48 & $2.2 \times 10^{8}$ & 219 & 93 & 2.4 & 69 & 12 \\
\hline \multirow[t]{3}{*}{$521 \mathrm{~d}$} & 8 & $7.7 \times 10^{5}$ & 131 & 28 & 4.7 & 36 & 19 \\
\hline & 22 & $9.4 \times 10^{7}$ & 151 & 29 & 5.2 & 36 & 14 \\
\hline & 48 & $1.1 \times 10^{8}$ & 112 & 20 & 5.6 & 40 & 26 \\
\hline
\end{tabular}

${ }^{a}$ The initial cell densities (cells $/ \mathrm{ml}$ ) for the cultures were as follows: $521,3.2 \times 10^{6} ; 521+\mathrm{cAMP}, 3.3 \times 10^{6} ; \mathrm{C}^{6} 02 \mathrm{a}, 2.8 \times 10^{6} ; 111$, $2.9 \times 10^{6} ; 521 \mathrm{~d}, 1.4 \times 10^{6}$.

${ }^{b}$ Cells in a random sample were counted, and the number of clusters of cells (units) was determined. For each unit, lateral buds were counted and the number of cells in the largest cluster was determined.

${ }^{\mathrm{c} S t r a i n} 521$ was grown in $1 \mathrm{ml}$ of PDB containing $25 \mathrm{mM}$ cAMP; all other cultures were grown in $5 \mathrm{ml}$ of PDB. The results of one experiment are presented; similar results were obtained in two additional experiments. 
A

\begin{tabular}{|c|c|c|}
\hline C221 & $\begin{array}{l}\text { C221 } \\
\text { C002a }\end{array}$ & c002a \\
\hline $\begin{array}{l}521 \\
\text { C221 }\end{array}$ & & $\begin{array}{l}\text { Co02a } \\
518\end{array}$ \\
\hline 521 & $\begin{array}{l}518 \\
521\end{array}$ & 518 \\
\hline $\begin{array}{l}221 \\
521\end{array}$ & & $\begin{array}{l}518 \\
111\end{array}$ \\
\hline 221 & $\begin{array}{l}111 \\
221\end{array}$ & 111 \\
\hline
\end{tabular}
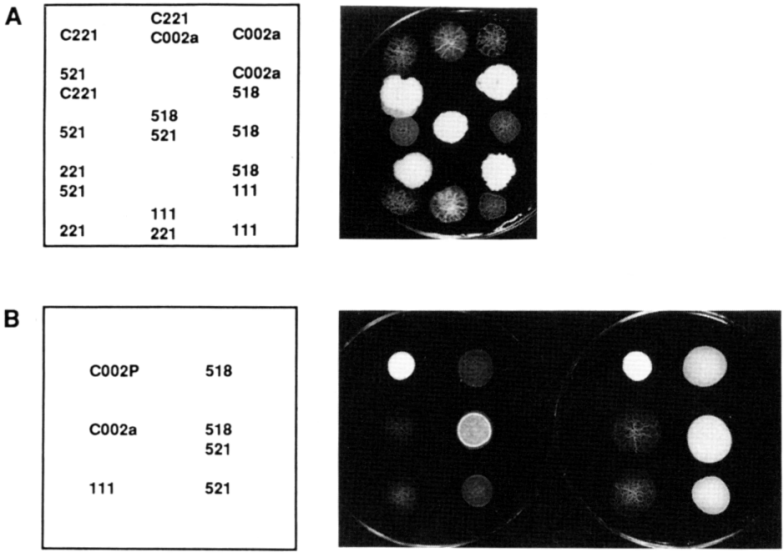

C
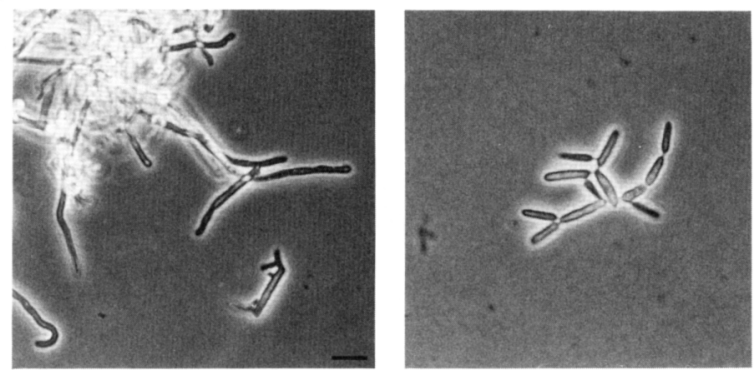

Figure 5. Response of $u b c 1$ mutants to mating and air. $(A)$ Colony morphology resulting from mating reactions on medium containing charcoal. The strains employed are listed at left; their genotypes are given in Table 2 . The reaction between wild-type strains $518(a 2 b 2)$ and $521(a 1 b 1)$ in the center shows the white aerial mycelium indicative of the filamentous growth resulting from a positive mating. Mating interactions between compatible wild-type and mutant strains yielded reactions of wild-type intensity. $(B)$ Colony morphology of wild-type and mutant strains grown on medium in petri plates sealed with parafilm (left) and in unsealed plates (right). The mating reaction between wild-type strains 518 and 521 gives a mycelial colony phenotype; strain C002P shows this phenotype by itself (Fig. 1C). In contrast with wild-type strains, strains 111 (ubc1-1) and C002a (uac1::ble ubc1-1) fail to become filamentous in response to free exchange of air. $(C)$ Photomicrographs of cells of strains 521 (left) and 521d (ubc1::hyg; right) grown for $48 \mathrm{hr}$ on water agar. The magnification is the same for both photographs. Bar, $10 \mu \mathrm{m}$.

the mating pathway leading to formation of the infectious dikaryon.

Haploid cells of $U$. maydis grown on solid culture medium with free exchange of air eventually form colonies that are covered with aerial mycelium (Fig. 5B). This response to air (presumably $\mathrm{O}_{2}$ or $\mathrm{CO}_{2}$ levels) does not occur when colonies form on culture medium in petri plates sealed with parafilm. Unlike wild-type cells, strains carrying the $u b c 1-1$ or the $u b c 1::$ hyg alleles were unable to respond to air by forming aerial hyphae on colonies. Other dimorphic fungi, for example, Mucor rouxii, also appear to alter their morphology in response to air (Orlowski 1991). Microscopic observations of $U$. maydis wild-type and mutant cells (Fig. $5 \mathrm{C}$ ) on water agar in unsealed plates also confirmed the inability of ubc1 mutants to form filaments. Under these conditions, wild-type cells formed small colonies and grew with a predominantly filamentous morphology. The ubc1 mutants also formed small colonies, but the cells retained the yeast-like morphology of wild-type strains. Interestingly, the $u b c 1$ mutants often formed chains of cells (Fig. 5C), in addition to the clusters of cells resulting from multiple budding. The persistent attachment of the cells in the chains is similar to the phenotype displayed by $S$. cerevisiae during pseudohyphal growth (Gimeno et al. 1992).

\section{Discussion}

\section{Defects in adenylate cyclase affect growth and morphogenesis}

We have shown that a mutation in the uac1 gene encoding adenylate cyclase results in filamentous growth in $U$. maydis and that cAMP restores budding growth to a uac1 mutant. Defects in adenylate cyclase result in a variety of phenotypes in other fungi. For example, mutations in the CYR1 gene of $S$. cerevisiae cause cells to arrest in the $G_{1}$ phase of the cell cycle and exogenous cAMP restores growth (Casperson et al. 1985; Kataoka et al. 1985; Ishikawa et al. 1988|. Disruption of the gene encoding adenylate cyclase in Schizosaccharomyces pombe results in a reduced growth rate, compared with wild-type cells, and a tendency to enter the sexual reproduction pathway in rich medium (Maeda et al. 1990). In $N$. crassa, mutation in the $c r-1$ gene results in reduced adenylate cyclase activity and lower levels of cAMP (Terenzi et al. 1976; Pall et al. 1981). Mutants carrying the defective $c r-1$ allele form small compact colonies that lack extensive hyphal development and display short aerial hyphae with tight clusters of dense conidia. Growth in the presence of cAMP restores a colony morphology more like that of wild-type cells. In general, it appears that adenylate cyclase and cAMP play roles in both growth and morphogenesis in fungi. Our results provide genetic evidence that the cAMP pathway plays a key role in the decision between budding and filamentous growth morphology in $U$. maydis. This finding may be generally true for smut pathogens because McCluskey et al. (1994) have reported a mutation (fil1) that causes filamentous growth in $U$. hordei. Budding growth is restored to strains carrying the fill mutation by addition of cAMP to culture medium. (D. Mills, pers. comm.).

\section{cAMP is implicated in dimorphism}

Biochemical evidence for a role for cAMP in morphogenesis has been described for a number of different pathogenic and saprophytic fungi, including many dimorphic species (Maresca et al. 1977; Medoff et al. 1981, 1987; Paris and Garrison 1983; Brunton and Gadd 1989). For example, an increase in intracellular cAMP has been reported during germ-tube formation and subsequent hy- 
phal growth in the dimorphic pathogens $H$. capsulatum (Maresca et al. 1977; Medoff et al. 1981), C. albicans (Niimi et al. 1980; Sabie and Gadd 1992), and Blastomyces dermatitidis (Paris and Garrison 1983). However, contradictory reports have appeared for C. albicans suggesting that factors (e.g., carbon source) other than cAMP control germ-tube formation (Cho et al. 1992) and even that an increase in cAMP levels promotes budding (Paveto et al. 1991). In M. rouxii, cAMP levels reportedly drop during the emergence of hyphal germ tubes and the level of cAMP remains low during hyphal growth compared with budding growth (for review, see Orlowski 1991). The situation for U. maydis appears to be similar to that described for $M$. rouxii in that low cAMP levels (e.g., as a result of a defect in adenylate cyclase) promote hyphal extension at the expense of budding growth. It should be noted that cAMP plays other roles in fungal morphogenesis in addition to influencing dimorphism. For example, a role for cAMP has been described recently for the regulation of infection structure formation in the rice blast fungus Magnaporthe grisea (Lee and Dean 1993).

Overall, biochemical studies have provided suggestive evidence for a role for cAMP in dimorphism, although a clear description of the mechanism of cAMP control of morphogenesis has not emerged. In addition, the ambiguous or contradictory results for $C$. albicans, which may be the result of different cultural and environmental conditions employed by various investigators, cause uncertainty about whether changes in cAMP levels are a secondary effect or a cause of the observed morphological changes. Our genetic evidence strongly supports a role for cAMP and, by implication, CAMP-dependent protein kinase, in determining growth morphology in $U$. maydis. It would be interesting to know whether defects in adenylate cyclase influence morphogenesis in other dimorphic fungi.

\section{A role for PKA in morphogenesis}

We have found that the filamentous phenotype resulting from a defect in adenylate cyclase could be suppressed by a mutation in the $u b c 1$ gene encoding the regulatory subunit of cAMP-dependent protein kinase. This result was not surprising considering the well-established role of the regulatory subunit as the major receptor for cAMP in eukaryotes (Taylor et al. 1990). In addition, mutations in the regulatory subunit gene $(B C Y 1)$ of $S$. cerevisiae suppress the growth defect of an adenylate cyclase mutant. Yeast strains with defects in $B C Y 1$ show a variety of additional phenotypes (Cannon and Tatchell 1987; Toda et al. 1987; Cannon et al. 1990). U. maydis strains carrying $u b c 1-1$ or $u b c 1::$ hyg mutations also have other phenotypes besides suppression of the filamentous growth that results from mutation in uac1; these include inhibition of cytokinesis, altered bud site selection, and attenuation of filamentous growth in response to air and mating interactions. These results suggest that phosphorylation events mediated by the catalytic subunit of PKA are involved in these processes.
Given the finding that a mutation in the gene for adenylate cyclase results in filamentous growth in $U$. maydis, we would predict that a defect in the gene encoding the catalytic subunit of PKA would result in a similar phenotype (i.e., mimic conditions of low cAMP). Although we have not yet tested this prediction for $U$. maydis, we note that a mutation in the cot-1 gene of $N$. crassa, which encodes a polypeptide with sequence similarity to the catalytic subunit of PKA, results in altered cell morphology (Yarden et al. 1992). In this case, cot-1 mutants have a defect in hyphal extension and show extensive branching.

In fungi, morphogenesis is determined by the deposition of new, vesicle-transported, cell wall material. A mathematical model has been proposed that provides for a hypothetical point for vesicle release, the vesicle supply center (vsc; Bartnicki-Garcia et al. 1989). Changes in the position and/or movement of the vsc yield entirely different shapes. This vsc model can account for most of the morphologies exhibited by fungi and includes shapes typical of $U$. maydis hyphal and yeast cells. An extension of the model is that factors influencing the position or movement of the vsc would have profound effects on cell shape; it is possible that phosphorylation by PKA may be such a factor in $U$. maydis.

\section{Protein phosphorylation and cytokinesis}

Mutants defective in $u b c 1$, and wild-type cells grown in cAMP, display the interesting phenotypes of multiple budding and frequent lateral budding, presumably as a result of activation of the catalytic subunit of PKA and phosphorylation of as yet unidentified proteins. The multiple-budding phenotype in $u b c 1$ mutants appears to result from a defect in the separation (cytokinesis) of mother and daughter cells. Daughter cells remain attached and continue to initiate buds at apical or lateral positions. Multiple-budding phenotypes have been described for other fungi. For example, C. albicans reportedly displays a multiple-budding phenotype under conditions otherwise conducive to germ-tube formation, that is, upon stimulation of adenylate cyclase activity by treatment with glucagon (Paveto et al. 1990). A multiplebudding phenotype is also found for mutants of $S$. cerevisiae defective in the TPD1, TPD $3, C D C 55$, or YCK2 genes (Healy et al. 1991; van Zyl et al. 1992; Robinson et al. 1993, 1994). These genes encode polypeptides with high homology to protein phosphorylase $2 \mathrm{C}$, the A and B regulatory subunits of mammalian protein phosphatase $2 \mathrm{~A}$, and casein kinase I, respectively. The results in $S$. cerevisiae suggest that phosphorylation and dephosphorylation events control the function of a substrate involved in cytokinesis. Our results indicate that PKA may at least partially fulfill the phosphorylation role in $U$. maydis.

Persistent attachment between mother and daughter cells also occurs during pseudohyphal growth in response to nitrogen starvation in $S$. cerevisiae. The constitutive activation of the RAS-adenylate cyclase path- 
way enhances pseudohyphal growth, thus implicating cAMP in the process (Gimeno et al. 1992). Pseudohyphal growth requires the bipolar budding pattern exhibited by $a / \alpha$ diploid cells; this pattern is established from the default random pattern by the actions of the BUD1, $B U D 2$, and BUD5 genes (for review, see Drubin 1991; Nelson 1992). Other genes, for example, ELM1, ELM2, and ELM3 (elongated morphology), also play a role in morphogenesis in S. cerevisiae (Blacketer et al. 1993). Mutations in these genes cause pseudohyphal growth; the ELM1 gene encodes a novel protein kinase that appears to interact with the product of the CDC55 gene (Blacketer et al. 1993). Genes encoding type 1-related protein phosphatases have also been found to play a role in pseudohyphal growth in S. cerevisiae (Lee et al. 1993) and a casein kinase II homolog recently has been found to play a role in polarized growth in $S$. pombe (Snell and Nurse 1994). As with cytokinesis in $S$. cerevisiae, these studies point to protein phosphorylation as a regulatory function for cell elongation and pseudohyphal growth.

\section{Budding, $C A M P$, and mating}

The finding that a defect in adenylate cyclase results in filamentous growth in $U$. maydis indicates that activation of PKA promotes budding growth. In addition, PKA appears to play a role in determining the position of the bud (lateral vs. apical). Lateral budding in $u b c 1-1 \mathrm{mu}-$ tants and in wild-type cells exposed to cAMP must result from a defect in the position of the bud site at initiation. Mating interactions between haploid cells of $U$. maydis, governed by the $a$ and $b$ loci, also influence morphogenesis by causing the cessation of budding growth and the establishment of the filamentous, infectious dikaryon. A connection between PKA and the mating pathway is indicated by the fact that mating reactions between strains carrying mutations in the $u b c 1$ gene fail to form the vigorous filaments indicative of the infectious dikaryon. In addition, a connection is suggested by the fact that compatible strains carrying the $u b c 1-1$ mutation are attenuated for pathogenicity, a function that requires mating and the establishment of the filamentous dikaryon (S. Gold, unpubl.). Fusion events are not reduced in wildtype strains in the presence of $25 \mathrm{mM}$ cAMP, a condition that simulates the phenotype of the $u b c 1-1$ mutant $\mid C$. Laity, unpubl.). Therefore, the $u b c 1-1$ defect probably interferes with the establishment or maintenance of filamentous growth because the presence of defective regulatory subunits leads to constitutive activation of PKA, a situation that promotes budding growth. That is, in matings between ubc1-1 mutants, there may be a competition between the regulatory influence of heterozygosity at the $b$ mating-type locus and the activity of the catalytic subunit of PKA. It should be kept in mind, however, that PKA in $U$. maydis undoubtedly has other roles in addition to the regulation of cytokinesis and bud position.

The connection between morphogenesis, cAMP, and mating in $U$. maydis is interesting when considered in the context of bud site selection in S. cerevisiae. The analysis of budding in $S$. cerevisiae has identified a number of genes involved in budding pattern (e.g., $B U D 3$ and $B U D 4$ ), bud site assembly (e.g., BEM1), and cytoskeleton assembly (e.g., CDC10) (Chant and Herskowitz 1991; Chenevert et al. 1992; for review, see Drubin 1991). Presumably, similar functions are utilized by $U$. maydis to establish budding growth. To switch to filamentous growth, these functions might be directly or indirectly repressed by $b$-locus-encoded regulatory proteins. In $S$. cerevisiae, mating or cell type regulation of budding pattern may exist; that is, it has been proposed that the $B U D 3$ and $B U D 4$ genes are negatively regulated by homeo domain-containing polypeptides encoded by the MATa/MATa loci (Chant and Herskowitz 1991). The $B U D 3$ and $B U D 4$ genes are required for establishing the axial budding pattern of haploid cells; these genes may be inactive in diploid cells that encode the a $1 / \alpha 2$ repressor and that display the polar budding pattern required for pseudohyphal growth. The $b$ mating-type locus of $U$. maydis also encodes polypeptides with homeo domainlike motifs; dimers between polypeptides encoded by different $b$ alleles are believed to regulate the switch from budding to filamentous growth (Gillissen et al. 1992). Therefore, when cells have mated, it is possible that $U$. maydis employs $b$-encoded regulatory factors to turn off the expression of genes whose products are required for budding. This scenario would be similar to the proposed al $/ \alpha 2$ regulation of the $B U D 3$ and $B U D 4$ genes, except the $\mathrm{b}$ proteins in $U$. maydis would repress budding and promote filamentous growth. Our data suggest that PKA phosphorylates factors required for budding; the absence of these factors, for example, in cells heterozygous for $b$, presumably results in filamentous growth by default. The dual regulation of filamentous growth in $U$. maydis by mating and environmental signals is summarized in Figure 6.

\section{Summary}

In summary, we have isolated and characterized the genes encoding adenylate cyclase and the regulatory subunit of PKA from $U$. maydis. The analysis of mutants with defects in these genes demonstrates that the cAMP pathway plays a key role in the decision to grow by budding versus hyphal extension (dimorphism). In addition, the phenotypes of mutants defective in the regulatory subunit of PKA indicate that phosphorylation events mediated by PKA control the ability of cells to bud, the separation of mother and daughter cells, and the position of bud formation. Mutations in the $u b c 1$ gene encoding the regulatory subunit of PKA also attenuate the filamentous growth and the pathogenicity that normally result from mating interactions. Overall, these findings provide important insights into the regulation of dimorphic growth in a fungal pathogen. The information obtained for $U$. maydis promises to have broad applicability, given the probable role of cAMP in dimorphic growth in other pathogenic fungi. 


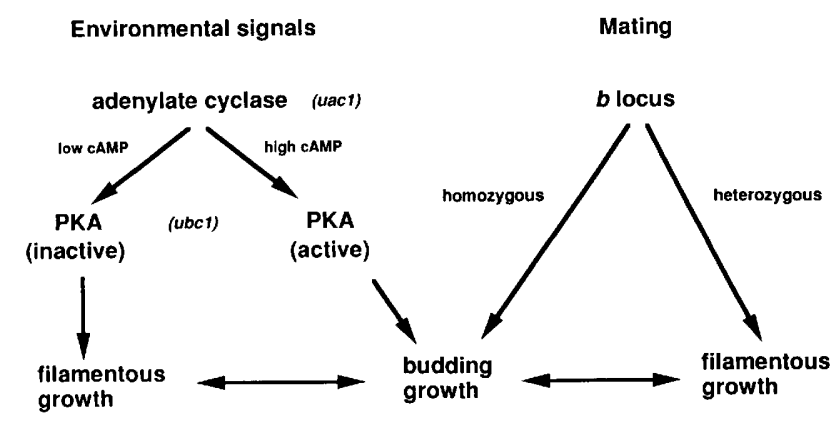

Figure 6. Diagram of environmental and mating control of dimorphism in $U$. maydis. Two pathways are shown to control the decision of $U$. maydis to grow with a budding or a filamentous morphology. That is, two different sets of factors /mating and environmental) trigger filamentous growth; budding growth occurs in nonmated cultures under conditions that result in high cAMP levels. Note that the $a$ locus of $U$. maydis, which encodes pheromones and pheromone receptors (Bölker et al. 1992), also influences filamentous growth, presumably through a pathway linked to the $b$-encoded regulatory function (Spellig et al. 1994). Free exchange of air during growth is one environmental signal known to trigger filamentous growth in $U$. maydis (Fig. 5B). Other environmental signals may include nutrient availability and mating pheromones (Kernkamp 1939; Snetselaar and Mims 1992; Spellig et al. 1994).

\section{Materials and methods}

Fungal and bacterial strains, growth conditions, and transformation

The $U$. maydis strains employed in this study are listed in Table 2 . The uac1 disruption strain C002P was constructed by insertion of a phleomycin resistance marker (ble; Gold et al. 1994) at a HindIII site at codon 899 (Fig. 2). This strain was the recipient of the pFuz60 cosmid that confers hygromycin $B$ resistance and carries the uac1 gene (Barrett et al., 1993). The strain C002a (uac1::ble $u b c 1-1$ ) was the recipient of the pUBC1 cosmid carrying the hygromycin resistance marker and the $u b c 1$ gene (Fig. 1). The $u b c 1$ disruption strain $521 \mathrm{~d}$ was constructed by insertion of a $2.7-\mathrm{kb}$ Bam HI-BglII fragment specifying hygromycin resistance into a unique BgIII site at codon 360. Strains C221, 111 , and 221 were obtained as progeny from a cross between strains C002a and 518. The Escherichia coli strain DH5 $\alpha$ (Bethesda Research Laboratories| was utilized for standard DNA manipulations (Sambrook et al. 1989), and strain DH10B (Bethesda Research Laboratories) was used for electroporation.

Table. 2. U. maydis strains

\begin{tabular}{lll}
\hline Strain & Genotype & Reference \\
\hline 521 & $a 1$ b1 & Kronstad and Leong (1989) \\
518 & $a 2$ b2 & $\begin{array}{l}\text { Kronstad and Leong (1989) } \\
\text { this work }\end{array}$ \\
C002P & $a 1$ b1 uac1::ble & this work \\
C002a & $a 1$ b1 uac1::ble ubc1-1 & this work \\
C221 & $a 2$ b2 uac1::ble ubc1-1 & this work \\
111 & $a 1$ b1 ubc1-1 & this work \\
221 & $a 2$ b2 ubc1-1 & this wack \\
C221 & $a 2$ b2 uac1::ble ubc1-1 & this work \\
$521 \mathrm{~d}$ & $a 1$ b1 ubc1::hyg & this work \\
\hline
\end{tabular}

Growth conditions for $U$. maydis and mutagenesis with ultraviolet light were as described previously (Barrett et al. 1993). AMP, dAMP, and cGMP (Sigma Chemical Company) were added to solid and liquid potato dextrose medium (PDA, PDB; Difco) at a concentration of $25 \mathrm{~mm}$. U. maydis transformations were performed by established methods (Tsukuda et al. 1988).

\section{DNA manipulations}

Total $U$. maydis nucleic acid was isolated by disruption of cells with glass beads and extraction with phenol (Kronstad and Leong 1989). Nucleotide sequence determination was performed with the T7 sequencing kit (Pharmacia). Fragments for sequencing were subcloned in the vector pUC128 (Keen et al. 1988) or pBluescript KS + (Stratagene), and nested deletions were produced with the Erase-a-Base deletion kit (Promega Biotech). Restriction and modifying enzymes were purchased from Bethesda Research Laboratories, Boerhinger Mannheim, Promega Biotech, or Pharmacia. A cDNA library was constructed in the phage vector Uni ZAP XR (Stratagene) from polyadenylated RNA purified from a mating mixture of strains 518 and 521 grown on double complete medium containing $1 \%$ charcoal (Holliday 1974). The library was screened by plaque hybridization (Sambrook et al. 1989) using the 4.7-kb BamHI fragment (C fragment; Barrett et al. 1993) of uac1 labeled with ${ }^{32} \mathrm{P}$ (Oligolabeling kit, Pharmacia). Southern hybridization analysis, to confirm the presence of disruption mutations in strains C002P (uac1::ble) and $521 \mathrm{~d}$ (ubc1::hyg), was carried out using Zetabind membranes (AMF Cuno) according to the manufacturer's instructions, except that dextran sulfate was omitted. The $4.7-\mathrm{kb}$ BamHI fragment of uac1 and a 2.6-kb SacI fragment of $u b c 1$ were used as hybridization probes. For each gene, insertion of the antibiotic resistance marker resulted in loss of a restriction fragment of wild-type size and the appearance of a novel fragment of the size expected from the insertion construct. RNA blot analysis was carried out as described previously (Barrett et al. 1993) using the $2.6-\mathrm{kb}$ SacI fragment of $u b c 1$ as a hybridization probe. Reverse transcriptase-polymerase chain reaction (RT-PCR) was employed to determine whether an intron was present in the $u b c 1$ gene. This analysis was carried out as described (Kawasaki 1990) using primers IN1 (AAGATCTCAATCGTGATG; codons 12-18) and IN3 (CTGAGCGCCTTGTTCGATCACAG; codons 239-246).

\section{Microscopy}

Colony morphology on PDA was photographed using a Wild M-5 dissecting microscope. Specimens for scanning electron and fluorescence microscopy were grown to mid- to late logarithmic phase in PDB with hygromycin $(50 \mu \mathrm{g} / \mathrm{ml})$ or cAMP $(25$ $\mathrm{mM})$. Scanning electron microscopy was carried out using a Hitachi S-4100 microscope. For fluorescence microscopy, cells were mounted in $0.7 \%$ low melting point agarose containing 5 $\mu \mathrm{g} / \mathrm{ml}$ of Calcofluor white and $1 \mu \mathrm{g} / \mathrm{ml}$ of DAPI (Sigma Chemical Co.) and photographed with a Zeiss Axiophot (Carl Zeiss, D-7082 Oberkochen) microscope using UV excitation. Brightfield light microscopy was also performed with a Zeiss Axiophot microscope.

\section{Analysis of multiple budding}

Cells for the analysis of budding were grown on PDA medium for 2 days at $30^{\circ} \mathrm{C}$ and used to inoculate $5 \mathrm{ml}$ of PDB medium with or without $25 \mathrm{mM}$ cAMP. These cultures were grown to saturation $(48 \mathrm{hr})$ at $30^{\circ} \mathrm{C}$ and $200 \mathrm{rpm}$ and diluted $1: 100$ into the same medium. Samples $\{50 \mu \mathrm{l}\}$ were removed and characterized 
for cell density; a minimum of 100 cells were observed for each sample, and the number of cell clusters and lateral buds were determined. Lateral buds were defined as those produced at right angles from the axis of the mother cell. The maximum number of cells per cluster was determined for the largest cluster observed in each sample: Average cells/cluster = total cells/ clusters.

\section{Acknowledgments}

We thank Arthur Yee, Guus Bakkeren, Michael Weis, and Don Moerman for help with the preparation of the manuscript and with photography. This work was supported by research and strategic grants from the Natural Sciences and Engineering Research Council of Canada.

The publication costs of this article were defrayed in part by payment of page charges. This article must therefore be hereby marked "advertisement" in accordance with 18 USC section 1734 solely to indicate this fact.

\section{Note}

The accession numbers for the sequences reported in this article are L33918 (uac1) and L33917 (ubc1).

\section{References}

Barrett, K., S. Gold, and J.W. Kronstad. 1993. Identification and complementation of a mutation to constitutive filamentous growth in Ustilago maydis. Mol. Plant-Microbe Interact. 6: 274-283.

Bartnicki-Garcia, S., F. Hergert, and G. Gierz. 1989. Computer simulation of fungal morphogenesis and the mathematical basis for hyphal (tip) growth. Protoplasma 153: 46-57.

Blacketer, M. J., C.M. Koehler, S.G. Coats, A.M. Myers, and P. Madaule. 1993. Regulation of dimorphism in Saccharomyces cerevisiae: Involvement of the novel protein kinase homolog Elmlp and protein phosphatase 2A. Mol. Cell. Biol. 13: $5567-5581$.

Bölker, M., M. Urban, and R. Kahmann. 1992. The a mating type locus of $U$. maydis specifies cell signalling components. Cell 68: 441-450.

Brunton, A.H. and G.M. Gadd. 1989. The effect of exogenouslysupplied nucleosides and nucleotides and the involvement of adenosine $3^{\prime}: 5^{\prime}$-cyclic monophosphate (cyclic AMP) in the yeast mycelium transition of Ceratocystis (= Ophiostoma) ulmi. FEMS Microbiol. Lett. 60: 49-54.

Cannon, J.F. and K. Tatchell. 1987. Characterization of Saccharomyces cerevisiae genes encoding subunits of cyclic AMPdependent protein kinase. Mol. Cell. Biol. 7: 2653-2663.

Cannon, J.F., R. Gitan, and K. Tatchell. 1990. Yeast cAMP-dependent protein kinase regulatory subunit mutations display a variety of phenotypes. J. Biol. Chem. 265: 11897-11904.

Casperson, G.F., N. Walker, and H.R. Bourne. 1985. Isolation of the gene encoding adenylate cyclase in Saccharomyces cerevisiae. Proc. Natl. Acad. Sci. 82: 5060-5063.

Chant, J. and I. Herskowitz. 1991. Genetic control of bud site selection in yeast by a set of gene products that constitute a morphogenetic pathway. Cell 65: 1203-1212.

Chenevert, J., K. Corrado, A. Bender, J. Pringle, and I. Herskowitz. 1992. A yeast gene (BEM1) necessary for cell polarization whose product contains two SH3 domains. Nature 356: 7779.

Cho, T., H. Hamatake, H. Kaminishi, Y. Hagihara, and K. Watanabe. 1992. The relationship between cyclic adenosine 3': 5'-monophosphate and morphology in exponential phase Candida albicans. I. Med. Vet. Mycol. 30: 35-42.

Christensen, J.J. 1963. Corn Smut caused by Ustilago maydis. 1963. Monograph no. 2. American Phytopathological Society, Saint Paul, MN.

Cutler, J.E. 1991. Putative virulence factors of Candida albicans. Annu. Rev. Microbiol. 45: 187-218.

Devereux, J., P. Haeberli, and O. Smithies. 1984. A comprehensive set of sequence analysis programs for the VAX. Nucleic Acids Res. 12: 387-395.

Drubin, D.D. 1991. Development of cell polarity in budding yeast. Cell 65: 1093-1096.

Froeliger, E.H. and S.A. Leong. 1991. The $a$ mating-type genes of Ustilago maydis are idiomorphs. Gene 100: 113-122.

Gillissen, B., J. Bergmann, C. Sandman, M. Schoeer, M. Bölker, and R. Kahmann. 1992. A two-component regulatory system for self/non-self recognition in U. maydis. Cell 68: 647-657.

Gimeno, C.J., P.O. Ljungdahl, C.A. Styles, and G.R. Fink. 1992. Unipolar cell divisions in the yeast $S$. cerevisiae lead to filamentous growth: Regulation by starvation and RAS. Cell 68: $1077-1090$.

Gold, S.E., G. Bakkeren, J. Davies, and J.W. Kronstad. 1994. Three selectable markers for transformation of Ustilago maydis. Gene 142: 225-230.

Healy, A.M., S. Zolnierowicz, A.E. Stapleton, M. Goebl, A.A. DePaoli-Roach, and J.R. Pringle. 1991. CDC55, a Saccharomyces cerevisiae gene involved in cellular morphogenesis: Identification, characterization, and homology to the B subunit of mammalian type $2 \mathrm{~A}$ protein phosphatase. Mol. Cell. Biol. 11: 5767-5780.

Holliday, R. 1974. Ustilago maydis. In Handbook of genetics (ed. R.C. King), Vol. 1, pp. 575-595. Plenum, New York.

Ishikawa, T., K. Matsumoto, and I. Uno. 1988. Yeast mutants altered in the cAMP cascade system. Methods Enzymol. 159: $27-42$.

Kataoka, T., D. Broek, and M. Wigler. 1985. DNA sequence and characterization of the $S$. cerevisiae gene encoding adenylate cyclase. Cell 43: 493-505.

Kawasaki, E.S. 1990. Amplification of RNA. In PCR protocols: A guide to methods and applications (ed. M.A. Innis, D.H. Gelfand, J.J. Sninsky, and T.J. Whitel, pp. 21-27. Academic Press, San Diego, California.

Keen N.T., S. Tamaki, D. Kobayashi, and D. Trollinger. 1988. Improved broad-host-range plasmids for DNA cloning in gram-negative bacteria. Gene 70: 191-197.

Kernkamp, M.F. 1939. Genetic and environmental factors affecting growth types of Ustilago zeae. Phytopathology 29: $473-484$

Kore-eda, S., T. Murayama, and I. Uno. 1991. Isolation and characterization of the adenylate cyclase structural gene of $\mathrm{Neu}$ rospora crassa. Ipn. I. Genet. 66: 317-334.

Kronstad, J.W. and S.A. Leong. 1989. Isolation of two alleles of the $b$ locus of Ustilago maydis. Proc. Natl. Acad. Sci. 86: 978-982.

- 1990. The $b$ mating-type locus of Ustilago maydis contains variable and constant regions. Genes \& Dev. 4: 1384 1395.

Lee, H.Y. and R.A. Dean. 1993. cAMP regulates infection structure formation in the plant pathogenic fungus Magnaporthe grisea. Plant Cell 5: 693-700.

Lee, K.S., L.K. Hines, and D.E. Levin. 1993. A pair of functionally redundant yeast genes (PPZ1 and PPZ2) encoding type 1-related protein phosphatases function within the $\mathrm{PKC1}$ mediated pathway. Mol. Cell. Biol. 13: 5843-5853.

Maeda, T., N. Mochizuki, and M. Yamamoto. 1990. Adenylyl cyclase is dispensable for vegetative cell growth in the fis- 
sion yeast Schizosaccharomyces pombe. Proc. Natl. Acad. Sci. 87: 7814-7818.

Maresca, B. and G.S. Kobayashi. 1989. Dimorphism in Histoplasma capsulatum: A model for the study of cell differentiation in pathogenic fungi. Microbiol. Rev. 53: 186-209.

Maresca, B., G. Medoff, D. Schlessinger, G.S. Kobayashi, and J. Medoff. 1977. Regulation of dimorphism in the pathogenic fungus Histoplasma capsulatum. Nature 266: 447-448.

Marques, M.V. and S.L. Gomes. 1992. Cloning and structural analysis of the gene for the regulatory subunit of cAMPdependent protein kinase in Blastocladiella emersonii. $J$. Biol. Chem. 267: 17201-17207.

McCluskey, K., J. Agnan, and D. Mills. 1994. Characterization of genome plasticity in Ustilago hordei. Curr. Genet. (in press).

Medoff, J., E. Jacobson, and G. Medoff. 1981. Regulation of dimorphism in Histoplasma capsulatum by cyclic adenosine 3': 5'-monophosphate. J. Bacteriol. 145: 1452-1455.

Medoff, J., A. Painter, and G. A. Kobayashi. 1987. Mycelial to yeast phase transitions of the dimorphic fungi Blastomyces dermatitidis and Paracoccidioides brasiliensis. J. Bacteriol. 169: 4055-4060.

Nelson, W.J. 1992. Regulation of cell surface polarity from bacteria to mammals. Science 258: $948-955$.

Niimi, M., K. Niimi, J. Tokunaga, and H. Nakayama. 1980. Changes in cyclic nucleotide levels and dimorphic transition in Candida albicans. J. Bacteriol. 142: 1010-1014.

Orlowski, M. 1991. Mucor dimorphism. Microbiol. Rev. 55: 234-258.

Pall, M.L., J.M. Trevillyan, and N. Hinman. 1981. Deficient cyclic adenosine $3^{\prime}$ : $5^{\prime}$-monophosphate control in mutants of two genes of Neurospora crassa. Mol. Cell. Biol. 1: 1-8.

Paris, S. and R.G. Garrison. 1983. Cyclic adenosine $3^{\prime}: 5^{\prime}$-monophosphate (c-AMP) as a factor in phase morphogenesis of Blastomyces dermatitidis. Mykosen. 27: 340-345.

Paveto, C., G. Egidy, M.A. Galvagno, and S. Passeron. 1990. A guanine nucleotide-sensitive, glucagon-stimulated adenylyl cyclase in Candida albicans: Effect of glucagon on cell morphology. Biochem. Biophys. Res. Commun. 167: 1177-1183.

Paveto, C., G. Mallo, G. Egidy, M.A. Galvagno, and S. Passeron. 1991. Activation of the cAMP cascade by steroidogenic hormones and glucagon in the pathogenic fungus Candida albicans. Cell Biol. Int. Rep. 15: 169-178.

Puhalla, J.E. 1970. Genetic studies on the $b$ incompatibility locus of Ustilago maydis. Genet. Res. Camb. 16: 229-232.

Robinson, L.C., M.M. Menold, S. Garrett, and M.R. Culbertson. 1993. Casein kinase I-like protein kinases encoded by $Y C K 1$ and YCK2 are required for yeast morphogenesis. Mol. Cell. Biol. 13: 2870-2881.

Robinson, M.K., W.H. van Zyl, E.M. Phizicky, and J.R. Broach. 1994. TPD1 of Saccharomyces cerevisiae encodes a protein phosphatase 2C-like activity implicated in tRNA splicing and cell separation. Mol. Cell. Biol. 14: 3634-3645.

Sabie, F.T. and G.M. Gadd. 1992. Effect of nucleosides and nucleotides and the relationship between cellular adenosine $3^{\prime}: 5^{\prime}$ - cyclic monophosphate (cyclic AMP) and germ tube formation in Candida albicans. Mycopathology 119: 147156.

Sambrook, J., E.F. Fritsch, and T. Maniatis. 1989. Molecular cloning: A laboratory manual, 2nd ed. Cold Spring Harbor Laboratory Press, Cold Spring Harbor, New York.

Schulz, B., F. Banuett, M. Dahl, R. Schlessinger, W. Schafer, T. Martin, I. Herskowitz, and R. Kahmann. 1990. The $b$ alleles of $U$. maydis, whose combinations program pathogenic development, code for polypeptides containing a homeodomain-related motif. Cell 60: 295-306.
Silva, J. 1972. Alleles at the $b$ incompatibility locus in Polish and North American populations of Ustilago maydis (DC) Corda. Physiol. Plant Pathol. 2: 333-337.

Snell, V. and P. Nurse. 1994. Genetic analysis of cell morphogenesis in fission yeast: A role for casein kinase II in the establishment of polarized growth. EMBO I. 13: 2066-2074.

Snetselaar, K.M. and C.W. Mims. 1992. Sporidial fusion and infection of maize seedlings by the smut fungus Ustilago maydis. Mycologia 84: 193-203.

Spellig, T., M. Bölker, F. Lottspeich, R.W. Frank, and R. Kahmann. 1994. Pheromones trigger filamentous growth in Ustilago maydis. EMBO J. 13: 1620-1627.

Taylor, S.S., J.A. Buechler, and W. Yonemoto. 1990. cAMP-dependent protein kinase: Framework for a diverse family of regulatory enzymes. Annu. Rev. Biochem. 59: 971-1005.

Terenzi, H.F., M.M. Flawia, M.T. Tellez-Inon, and H.N. Torres. 1976. Control of Neurospora crassa morphology by cyclic adenosine $3^{\prime}$ : $5^{\prime}$-monophosphate and dibutyryl cyclic adenosine $3^{\prime}$ : 5'-monophosphate. I. Bacteriol. 126: 91-99.

Toda, T., S. Cameron, P. Sass, M. Zoller, J.D. Scott, B. McMullen, M. Hurwitz, E.G. Krebs, and M. Wigler. 1987. Cloning and characterization of $B C Y 1$, a locus encoding a regulatory subunit of the cyclic AMP-dependent protein kinase in Saccharomyces cerevisiae. Mol. Cell. Biol. 7: 1371-1377.

Tsukuda, T., S. Carleton, S. Fotheringham, and W.K. Holloman. 1988. Isolation and characterization of an autonomously replicating sequence from Ustilago maydis. Mol. Cell. Biol. 8: 3703-3709.

van Zyl, W., W. Huang, A.A. Sneddon, M. Stark, S. Camier, M. Werner, C. Marck, A. Sentenac, and J.R. Broach. 1992. Inactivation of the protein phosphatase $2 \mathrm{~A}$ regulatory subunit $\mathrm{A}$ results in morphological and transcriptional defects in Saccharomyces cerevisiae. Mol. Cell. Biol. 12: 4946-4959.

Yarden, O., M. Plamann, D.J. Ebbole, and C. Yanofsky. 1992. cot-1, a gene required for hyphal elongation in Neurospora crassa, encodes a protein kinase. $E M B O$ I. 11: 2159-2166.

Yee, A.R. and J.W. Kronstad. 1993. Construction of chimeric alleles with altered specificity at the $b$ incompatibility locus of Ustilago maydis. Proc. Natl. Acad. Sci. 90: 664-668. 


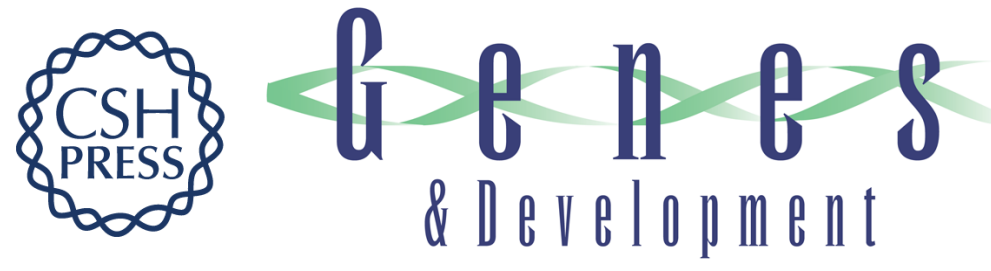

\section{cAMP regulates morphogenesis in the fungal pathogen Ustilago maydis.}

S Gold, G Duncan, K Barrett, et al.

Genes Dev. 1994, 8:

Access the most recent version at doi:10.1101/gad.8.23.2805

References This article cites 57 articles, 24 of which can be accessed free at:

http://genesdev.cshlp.org/content/8/23/2805.full.html\#ref-list-1

License

Email Alerting

Service right corner of the article or click here.

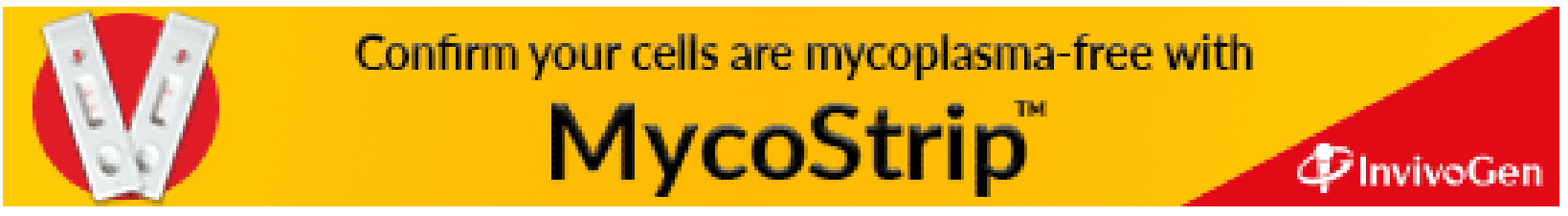

